\title{
A INTERLEUCINA-10 E SEU PAPEL NOS CARCINOMAS MAMÁRIOS CANINOS
}

\author{
THE INTERLEUKIN-10 AND YOUR ROLE IN CANINE MAMMARY CARCINOMAS \\ E. GARRIDO ${ }^{1 *}$, T. L. L. CASTANHEIRA ${ }^{2}$, M. C. ROSOLEM ${ }^{2}$, A. MATSUI ${ }^{2}$, \\ R. O. VASCONCELOS
}

\begin{abstract}
RESUMO
A interleucina-10 (IL-10) pode estar relacionada aos mecanismos de evasão tumoral, promovendo a progressão do tumor. O objetivo deste trabalho foi determinar a relação entre a secreção de IL-10, o tipo histológico tumoral e a intensidade da reação inflamatória no sítio tumoral, comparando a imunomarcação de IL-10, por imuno-histoquímica, entre os grupos de amostras de carcinomas mamários e de tecido mamário hígido em cadelas. No presente estudo foi verificado um aumento significativo no número de células imunomarcadas no grupo carcinoma e, também, uma associação entre a intensidade da inflamação, a secreção de IL-10. Com este estudo pode-se concluir que o aumento na secreção de IL-10 influenciado pelo carcinoma mamário pode criar um microambiente favorável para a progressão do tumor, possivelmente pela supressão de citocinas pró-inflamatórias e pela proliferação de subtipos de linfócitos com efeito imunossupressor, como os linfócitos T regulatórios.
\end{abstract}

PALAVRAS-CHAVE: Câncer. Citocinas. Evasão tumoral. Reação inflamatória.

\section{SUMMARY}

The Interleukin-10 may related to tumor evasion mechanisms by promoting tumor progression. The objective of this study was to determine the relationship between IL-10 secretion, histologic tumor type and the intensity of the inflammatory reaction in the tumor site, comparing immunostaining of IL-10, by immunohistochemistry, between groups of carcinoma breast samples and breast tissue in healthy bitches. The present study found a significant increase in the number of immunostained cells in the carcioma group and an association between the intensity of inflammation and IL-10 secretion. With this study, we can concluded that the increase in IL-10, affected by mammary carcinoma secretion, can create a microenvironment advantageous to tumor progression, possibly due to the suppression of proinflammatory cytokines and the proliferation of subtype of lymphocyte with immunosuppressive effect, like regulatory T lymphocytes.

KEY-WORDS: Cancer. Cytokines. Inflammatory reaction. Tumor evasion.

\footnotetext{
${ }^{1}$ Aluno do Programa de Pós-Graduação em Medicina Veterinária da FCAV-UNESP.

${ }^{2}$ Departamento de Patologia Veterinária, FCAV-UNESP, Jaboticabal.

*Autor para correspondência: Endereço de correspondência: Instituto Federal do Norte de Minas Gerais, Km 02 da rodovia MG 404,

Salinas, MG. CEP 39560-000. E-mail do autor: garridovet@ gmail.com
} 


\section{INTRODUÇÃO}

$\mathrm{Na}$ imunologia tumoral existem dois mecanismos importantes: os mecanismos de imunovigilância e os mecanismos de evasão do sistema imune. Este último permite às células neoplásicas criarem um ambiente de tolerância, levando ao crescimento e à malignidade tumoral (SATYAM et al., 2011; DUNN et al., 2004). A malignidade dos tumores mamários pode estar relacionada com a resposta inflamatória induzida por linfócitos e outras células inflamatórias infiltradas no sítio de crescimento tumoral, tais como os macrófagos regulatórios M2 (REOME et al., 2004). Já a resistência envolve mecanismos de destruição das células tumorais, tanto pela ação da imunidade inata (macrófagos e células $\mathrm{NK}$ ), quanto pela adquirida, por meio de linfócitos $\mathrm{T}$, que desencadeiam uma resposta imune celular (ABBAS et al., 2012). Linfócitos T diferenciam-se em células $\mathrm{CD}^{+}$(HORIUCHI et al., 2007), que se subdividem em Th1 e Th2, com um perfil de citocinas específicas, que levam a uma resposta imune celular (Th1) ou humoral (Th2) (REED, 1995; YAMAZAKI et al., 2002; HORIUCHI, et al., 2007). O desequilíbrio para um perfil Th2 está relacionado com o desenvolvimento de diversos tumores, pela supressão da resposta antitumoral das células Th1 (SATYAM et al., 2011). A IL-10 está envolvida na inibição da ativação dos macrófagos, limitando a produção de IL1, IL-6, TNF- $\alpha$, bem como, a ativação antígenoespecífico dos linfócitos $\mathrm{T}$, pela regulação negativa das células apresentadoras de antígenos e inibição da expansão de células T pela inibição da produção de IL2. A sua produção aumenta a expressão de $\mathrm{MHC}$ em células $B$, inibe efeitos Th1, principalmente pela inibição da produção IFN- $\gamma$, inibe a liberação de citocinas a partir de macrófagos, e estimula a multiplicação de mastócitos. Um dos mecanismos pelo qual as células tumorais escapam do reconhecimento pelo sistema imunológico pode incluir a IL-10 (HODI \& SOIFFER, 2002). O objetivo deste trabalho foi determinar a relação entre a secreção de IL-10 com a presença de carcinomas caninos, o tipo histológico do tumor e a intensidade da reação inflamatória no sítio tumoral, por imuno-histoquímica.

\section{MATERIAL E MÉTODOS}

Foram colhidas 30 amostras de $0,5 \mathrm{~cm}$, com o auxílio de uma lâmina de bisturi $\mathrm{n}^{\circ} 24$, de tecido mamário de cadelas, sem predisposição de raça ou idade. As amostras de tecido mamário canino foram dividias em dois grupos: o controle $(\mathrm{n}=5) \mathrm{e}$ carcinomas simples $(\mathrm{n}=25)$. As amostras foram colhidas no Departamento de Patologia Veterinária e nos serviços de Obstetrícia e de Oncologia Veterinária da FCAV-UNESP. Os fragmentos, incluídos em parafina, foram submetidos à imuno-histoquímica com o anticorpo policlonal IL-10 (Biorbyt, cat. Orb), na diluição de 1:400, por meio do complexo de polímeros ligados a peroxidase Kit Revel, Spring, cat. $\mathrm{n}^{\circ}$ SPB125), conforme as seguintes etapas:

Etapa 1: Desparafinização dos cortes de mama em estufa a $60^{\circ} \mathrm{C}$ por uma hora, seguido de banhos em soluções de xilol (I e II), por 10 minutos cada. Após os cortes foram hidratados em baterias de álcool absoluto, $95 \%$ e $80 \%$ e, em seguida foram lavados 10 vezes em água destilada.

Etapa 2: Recuperação antigênica no vapor (panela Pascal, Dako, cód. S2800), com solução tampão de citrato de sódio $10 \mathrm{mM}(\mathrm{pH}$ 6,0).

Etapa 3: Bloqueio da peroxidase endógena foi feito com solução de peróxido de hidrogênio $(30 \mathrm{v} / \mathrm{v}) \mathrm{e}$ metanol a $8 \%$, à temperatura ambiente, em câmara úmida por 30 minutos.

Etapa 4: Bloqueio das proteínas inespecíficas realizado com produto comercial (Protein Block Serum-Free, Dako, cód. X0909), por 30 minutos, à temperatura ambiente.

Etapa 5: Incubação do anticorpo primário por 18 horas a $4^{\circ} \mathrm{C}$, em câmara úmida.

Etapa 6: Incubação do anticorpo secundário foi feita à temperatura ambiente, em câmara úmida, por 30 minutos. Entre cada uma das etapas descritas fez-se banhos com solução tampão Tris (pH 7,4).

Etapa 7: Detecção da imunomarcação com o cromógeno diaminobenzidina (Liquid DAB + Substrate Chromogen System, DAKO, cód. K3468), por 3 minutos.

Etapa 8: Contracoloração com Hematoxilina de Harris e montagem das lâminas com Entellan (Merck).

A densidade das células imunomarcadas foi determinada pela contagem de células em cinco campos de grande aumento (área de $0,19625 \mathrm{~mm}^{2}$ por campo) na obj. de 40x, em microscópio de luz Nikon E200. A média de células imunomarcadas foi determinada para cada amostra do grupo carcinomas e do controle. Para a análise estatística confrontou-se a densidade de células imunomarcadas para a IL-10 entre os grupos controle e carcinomas simples, pelo teste $\mathrm{T}$ de Student $(\alpha=5 \%)$. O teste para múltiplas médias de Student Newman Keuls (SNK) foi utilizado para avaliar as médias do grupo carcinoma simples, quando subdividido segundo seu padrão histológico em carcinomas papilares, tubulares ou sólidos. O teste exato de Fisher foi realizado para averiguar a relação entre os níveis categóricos de IL-10 (0-5) e os níveis categóricos de inflamação (0-3). Os níveis categóricos de IL-10 representam média de células secretoras da citocina e foram divididos da seguinte forma, escore 0 (média de zero a cinco células secretoras); escore 1 (seis a 25); escore 2 (26 a 49); escore 3 (50 a 74); escore 4 (75 a 99); e escore 5 (mais de 100 células secretoras). Para a inflamação os escores representam a presença de um infiltrado inflamatório ausente (0); discreto (1); moderado (2); ou severo (3). A divisão categórica pode ser vista na Tabela 1 . Os testes estatísticos foram realizados com o auxílio do programa estatístico SAS 9.1 (SAS Institute, Cary, NC, USA). 
Tabela 1 - Escores categóricos da média de células secretoras de IL-10 e de intensidade de inflamação utilizados neste estudo.

\begin{tabular}{cc}
\hline Escore para média de células secretoras de IL-10 & Média de células secretoras de IL-10 \\
\hline 0 & $0-5$ \\
1 & $5-25$ \\
2 & $26-49$ \\
3 & $50-74$ \\
4 & $75-99$ \\
5 & $>$ de 100 \\
\hline Escore para intensidade de inflamação & Ausência \\
1 & Discreto \\
2 & Moderado \\
3 & Severo de Infiltrado inflamatório \\
\hline
\end{tabular}

\section{RESULTADOS E DISCUSSÃO}

As células imunomarcadas para IL-10 apresentaram-se distribuídas difusamente nos tumores, principalmente nos carcinomas papilares e tubulares, sendo focal nos carcinomas sólidos. Leucócitos e células epiteliais malignas apresentaram secreção de IL-10 (Figura 1). O grupo controle apresentou marcação apenas em leucócitos. A densidade de células imunomarcadas para IL-10 foi maior no grupo dos carcinomas em relação ao grupo controle $(\mathrm{P}<0,0001)$ (Figura 2). As médias e o erro padrão foram 50,58 \pm 5,65 e 2,84 $\pm 0,89$ respectivamente. Quando o grupo de carcinomas foi subdividido, não houve diferença estatística entre os grupos com tumores papilares, tubulares ou sólidos entre si, porém, todos diferiram significativamente do grupo controle $(\mathrm{P}<0,00001)$. O escore da intensidade de inflamação apresentou oito amostras com escore $0 ; 18$ amostras com escore 1; três amostras com escore 2; e seis amostras com escore 3 (Tabela 2). Os níveis categóricos de IL-10 apresentaram oito amostras escore 0 ; cinco amostras escore 1; 12 amostras escore 2; três amostras escore 3; três amostras escore 4; e três amostras escore 5 (Tabela 3). O teste exato de Fisher mostrou haver relação direta entre os níveis de IL-10 e a intensidade da inflamação $(\mathrm{P}<0,0002)$.

Os dados encontrados nesse estudo demonstraram que o aumento da expressão de IL-10 está associado à presença de neoplasia mamária, mas não aos subtipos histológicos. Isto indica que não há uma diminuição na expressão desta citocina em tumores menos agressivos, evidenciando uma progressão contínua da sua produção no microambiente tumoral. IL-10 desenvolve importante papel na inibição da ativação de macrófagos e de linfócitos $\mathrm{T}$, principalmente, pela inibição da resposta Th1, decorrente da supressão da secreção de IFN- $\gamma$, que tem importante ação antitumoral e está normalmente suprimida durante o desenvolvimento tumoral (REOME et al., 2004; HODI \& SOIFFER, 2002).

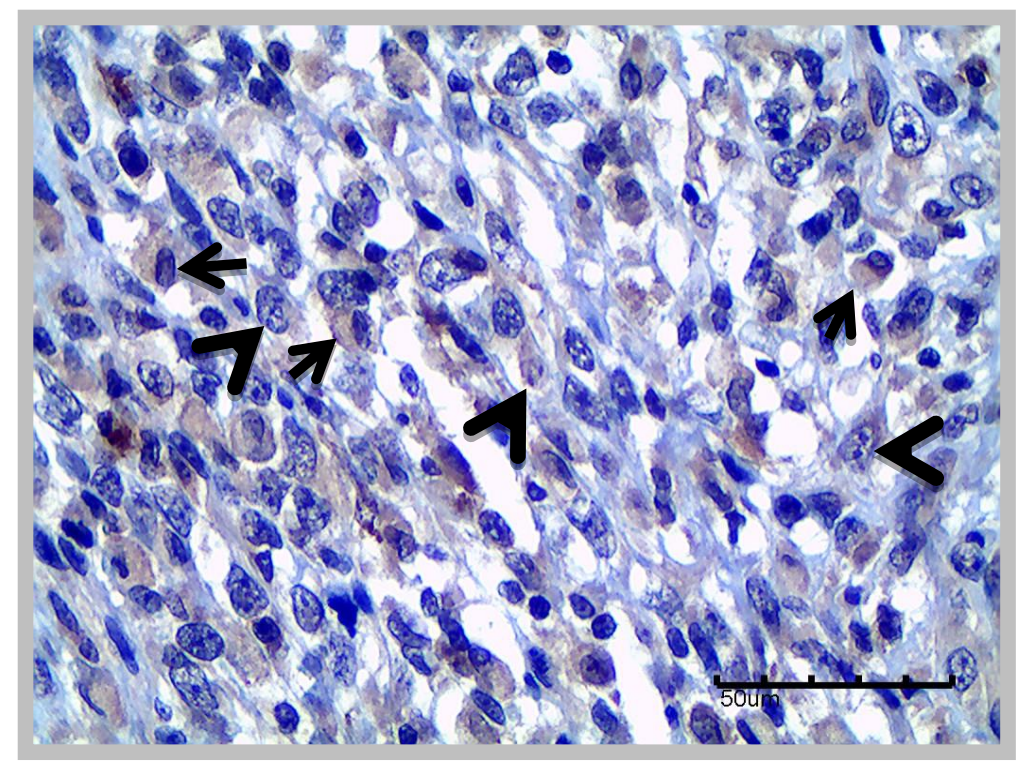

Figura 1 - Fotomicrografia de tecido mamário canino acometido por carcinoma mamário de padrão sólido. Notar leucócitos (setas) e células neoplásicas (cabeças de seta) imunomarcados pelo anticorpo IL-10. Complexo de polímeros ligados a peroxidase. Barra $=50 \mu \mathrm{m}$. 


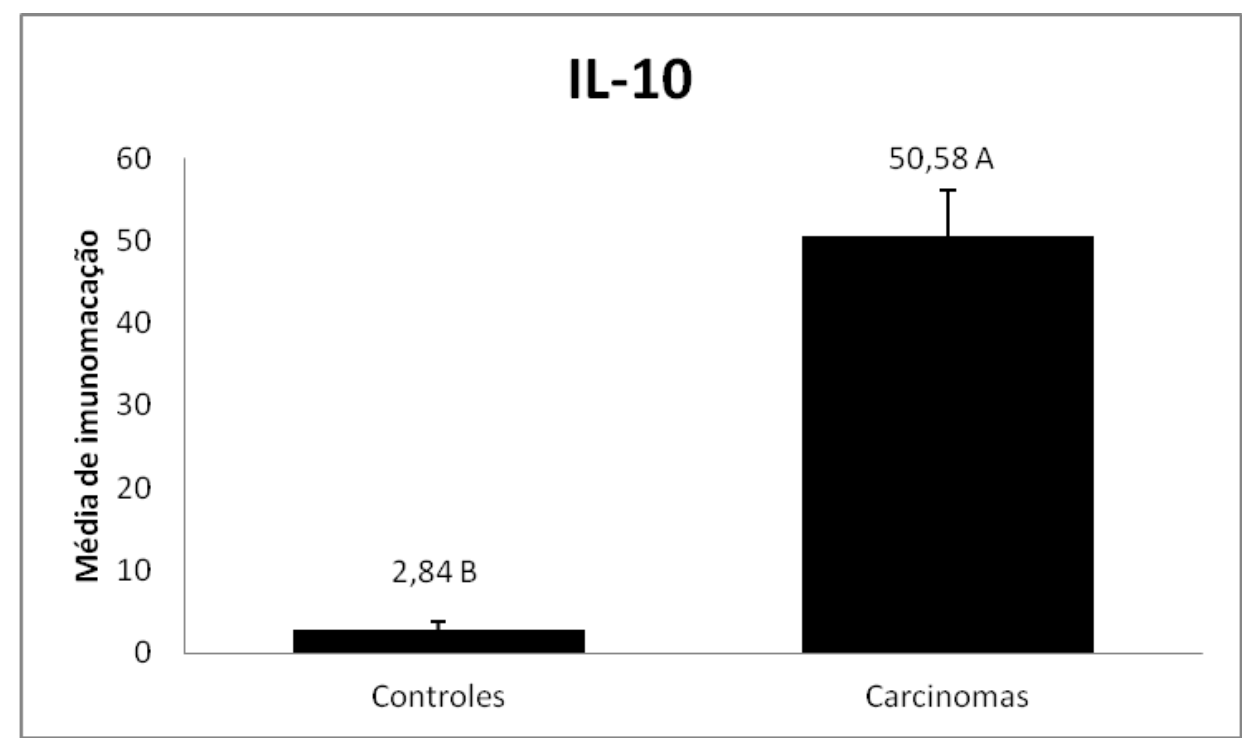

Figura 2 - Médias de células imunomarcadas para o anticorpo IL-10 no grupo controle e no grupo de cadelas acometidas por carcinoma mamário. Letras diferentes indicam diferença significativa pelo teste T de Student $(\alpha=5 \%)$.

Tabela 2 - Escore da intensidade de inflamação, número de amostras e frequências encontradas nos tecidos acometidos ou não por carcinomas mamários caninos utilizados no experimento.

\begin{tabular}{ccc}
\hline Escore & $\mathrm{N}^{\mathbf{o}}$ de amostras & Frequência $(\%)$ \\
\hline 0 & 8 & 22,86 \\
1 & 18 & 51,43 \\
2 & 3 & 8,57 \\
3 & 6 & 17,14 \\
\hline Total & 35 & 100 \\
\hline
\end{tabular}

Tabela 3 - Escore da média de células secretoras de IL-10, número de amostras e frequências encontradas nos tecidos acometidos ou não por carcinomas mamários caninos utilizados no experimento.

\begin{tabular}{ccc}
\hline Escore & $\mathrm{N}^{\mathrm{o}}$ de amostras & Frequência $(\%)$ \\
\hline 0 & 8 & 22,86 \\
1 & 5 & 14,28 \\
2 & 12 & 34,28 \\
3 & 4 & 11,44 \\
4 & 3 & 8,57 \\
5 & 3 & 8,57 \\
\hline Total & 35 & 100 \\
\hline
\end{tabular}

A relação direta entre a intensidade da inflamação e a imunomarcação para IL-10 sugere que o aumento na presença de linfócitos está vinculado a um aumento na presença de linfócitos $\mathrm{T}$ regulatórios (Tregs) no sítio tumoral, causando um incremento no infiltrado inflamatório, mas tornando-o imunologicamente comprometido. Os linfócitos Tregs são um constituinte particular da população de linfócitos T auxiliares (CD4+), que se diferenciam em Tregs na presença de IL-10 e suprimem a resposta imune contra o tumor (RISSETO et al., 2010). Esses efeitos supressivos têm ação direta sobre os linfócitos T CD4+, resultando em uma ineficiente ativação da imunidade celular. Eles são mediados pela produção de citocinas imunossupressoras (TGF- $\beta$ e IL-10) ou por contato direto entre as células (O’NEILL et al., 2009;
BILLER et al., 2007). No câncer há evidência de que as Tregs podem ser induzidas pelo tumor e podem suprimir a resposta do sistema imune aos antígenos tumorais (STANDISH et al., 2008), possivelmente pelo mimetismo das células tumorais na secreção de citocinas como evidenciado neste trabalho.

\section{CONCLUSÃO}

Concluímos que o aumento na secreção de IL10 pelo tecido mamário neoplásico cria um ambiente tumoral favorável para a progressão tumoral, possivelmente pela supressão de citocinas com ação antitumoral, como o IFN- $\gamma$ e a IL-2, como pelo aumento linfócitos $\mathrm{T}$ regulatórios, que ocorrem na presença de IL-10. 


\section{AGRADECIMENTOS}

À FAPESP (processo 2012/09385-0) pelo auxílio financeiro à pesquisa e pela bolsa de estudo (processo 2011/13896-7). Este trabalho é parte da Tese de Doutorado do primeiro autor. Os autores agradecem a Francisca de Assis Ardisson pelo processamento histológico das amostras de tecido mamário.

Estudo aprovado pela Comissão de Ética no Uso de Animais da FCAV-UNESP (CEUA protocolo $\left.n^{\circ} .005925 / 13\right)$.

\section{REFERÊNCIAS}

ABBAS, A. K.; LICHTMAN; PILLAI, S. Cellular and molecular immunology. 7.ed. Philadelphia: Elsevier Saunders, 2012. p.389-406.

BILLER, B. J.; ELMSLIE, R. E.; BURNETT, R. C.; AVERY, A. C.; DOW, S.W. Use of FoxP3 expression to identify regulatory $\mathrm{T}$ cells in healthy dogs and dogs with cancer. Veterinary Immunology and Immunopathology. v.116, p.69-78, 2007.

DUNN, G. P.; OLD, L. J.; SCHREIBER, R. D. The three Es of cancer immunoediting. Annual Review Immunology, v.22, p.211-7, 2004. Doi: 10.1146/annurev.immunol.22.012703.104803.

HODI, F. S.; SOIFFER, R. J. Interleukin. In: BERTINO, J. Encyclopedia of cancer. 2.ed. Waltham: Academic Press, 2002. p.530-31.

HORIUCHI, Y.; NAKAJIMA, Y.; NARIAI, Y.; ASANUMA, H.; KUWABARA, M. Th1/Th2 balance in canine peripheral blood lymphocytes - A flow cytometric study. Veterinary Immunology and Immunopathology, v.118, p.179-185, 2007.

O'NEILL, K.; GUTH, A.; BILLER, B.; ELMSLIE, R.; DOW, S. Changes in Regulatory T cells in dogs with cancer and associations with tumor type. Journal of Veterinary Internal Medicine. v.23, p.875-881, 2009.
REED, M. J. The discriminant-function test: a marker of Th1/Th2 cell cytokine secretion and breast tumor estrogen synthesis. Molecular Medicine Today, v.1, p.98-103, 1995.

REOME，J. B.; HYLIND, J. C.; DUTTON, R. W.; DOBRZANSKI, M. J. Type 1 and type 2 tumor infiltrating effector cell subpopulations in progressive breast cancer. Clinical Immunology, v.111, p.69-81, 2004.

RISSETO, K. C.; INDT, H.; SELTING, K. A.; VILLAMIL, J. A.; HENRY, C. J.; REINERO, C. R. Cloning and expression of canine CD25 for validation of an anti-human CD25 antibody to compare T regulatory lymphocytes in healthy dogs and dogs with osteosarcoma. Veterinary Immunology and Immunopathology. v.135, p.137-145, 2010.

SATYAM, A.; SINGH, P.; BADJATIA, N.; SETH, A.; SHARMA, A. A disproportion of Th1/Th2 cytokines with predominance of Th2 in urothelial carcinoma of bladder. Urologic Oncology, v.29, p.58-65, 2011.

STANDISH, L. J.; SWEET, E. S.; NOVACK, J.; WENNER, C. A.; BRIDGE, C.; NELSON, A.; MARTZEN, M.; TORKELSON, C. Breast cancer and immune system. Journal of the Society for Integrative Oncolology. v.6, n.4, p.158-68, 2008.

YAMAZAKI, K.; YANO, T.; KAMEYAMA, T.; SUEMITSU, R.; YOSHINO, I.; SUGIO, K. Clinical significance of serum $\mathrm{Th} 1 / \mathrm{Th} 2$ cytokines in patients with pulmonary adenocarcinoma. Surgery, v.131, p.236-41, 2002. 